Oswald, I.; Ashcroft, G. W.; Berger, R. J.; Eccleston, D.; Evans, J. I., and Thacore, V. R.: Some experiments in the chemistry of normal sleep. Brit. J. Psychiat. 112: 391-399 (1966).

Oswald, I.; Evans, J. I., and Lewis, S. A.: Addictive drugs cause suppression of paradoxical sleep with withdrawal rebound; in Steinberg Scientific basis of drug dependence, pp. 243-247 (Churchill, London 1969).

Oswald, I. and Thacore, V. R.: Amphetamine and phenmetrazine addiction. Physiological abnormalities in the abstinence syndrome. Brit. med. J. ii: 427-431 (1963) Rechtschaffen, A. and Kales, A. (eds.): A manual of standardized terminology, techniques and scoring system for sleep stages of human subjects. National Institute of Health Publication No. 204 (US Government Printing Office, Washington 1968). Shen, F. H.; Loh, H. H., and Way, E. L.: Brain serotonin turnover in morphine tolerant and dependent mice. J. Pharmacol, exp. Ther. 175: 427-434 (1970).

Way, E. L.: Role of serotonin in morphine effects. Fed. Proc. 31: 113-120 (1972). Wyatt, R. J.; Engelman, K.; Kupfer, D. J.; Scott, J.; Sjoerdsma, A., and Snyder, F.: Effect of parachlorophenylalanine on sleep in man. Electroenceph. clin. Neurophysiol. 27: 529-532 (1969).

Wyatt, R. J.; Zarcone, V.; Engelman, K.; Dement, W. C.; Snyder, F., and Sjoerdsma, A.: Effects of 5-hydroxy-tryptophan on the sleep of normal human subjects. Electroenceph. clin. Neurophysiol. 30: 505-509 (1971).

Author's address: Dr. K. Davison, Department of Psychological Medicine, Newcastle General Hospital, Newcastle-upon-Tyne NE4 6BE (England)

Sleep: Physiology, Biochemistry, Psuchology, Pharmacology, Clinical Implications. 1st Europ. Congr. Sleep Res., Basel 1972, pp. 601-606 (Karger, Basel 1973)

Polygraphic Investigations during the Terminal Stages of Coma and after Clinical Death

B. A§gian, L. Popoviciu and C. Sipos

Neurological Clinic, Tirgu-Mure?

We have performed polygraphic recordings in 8 cases of cerebral vascular coma until the occurrence of clinical death and again $1 \mathrm{~h}$ later. The duration of recordings varied from $1 \mathrm{~h} 49 \mathrm{~min}$ to $63 \mathrm{~h} 35 \mathrm{~min}$. We recorded the pneumogram, the ECG, ocular movements and 5 EEG derivations. Our observations concern mainly the eye movements that appeared during coma. 
Fig. 1. Four oscillating movements on the channel of eye movements (EM).

Fig. 2. a Ocular myocloniae of great amplitude and with the same frequency as the respiratory movements $(R)$. $b$ Intentional ocular myocloniae of little amplitude. Each myoclonus corresponds to a respiratory movement, $\mathrm{c}$ The ceasing of respiratory movements (apnea phase of Cheyne-Stokes) determines the cessation of the ocular myocloniae.

\section{Results and Discussions}

During cerebral-vascular coma we noticed longer or shorter periods of eye movements, classified by us in 5 different categories: (1) oscillating movements; (2) active ocular myoclonus [2, 3]; (3) sporadic ocular myoclonus;

(4) rhythmic ocular myoclonus, and (5) eye movements similar to those observed in paradoxical sleep.

1. Oscillating movements. These were always horizontal, appeared in periods of 8-10 min during which the frequency of oscillations was $8-12 / \mathrm{min}$ (fig. 1). We did not find a direct correlation between these oscillating movements

A?gian Investigations of Coma and Clinical Death 603

and the cardiac or pulmonary state. Therefore, the serious prognosis of oscillating movements does not relate to the vital cardio-respiratory functions but to other ponto-bulbar activities.

2. Active ocular myoclonus was observed in all the cases and its appearance was always related to the respiratory movements. They were observed especially in the terminal phases of coma when they lasted a long time, having sometimes high, sometimes low amplitude (fig. 2). When this active myoclonus appeared in Cheyne-Stokes respiration it stopped during the apnea phases of this type of respiration, marking in this way its direct relation to the breathing (fig. $2 \mathrm{c}$ ). Sometimes active ocular myoclonus appeared a long time before the terminal phase of coma but then it lasted only briefly (fig. 3). Figure 3 (below) shows an episode of 12 min when the myoclonus gradually increased and decreased.

3. Sporadic ocular myoclonus. Sometimes we observed some sporadic and irregular eye movements, unrelated to respiratory function and with no concomitant EEG changes; they were sometimes slow (fig. 4, I) other times rapid (fig. 4, II a).

4. Rhythmic ocular myoclonus. Either rhythmic from the beginning or occurred by turning a sporadic myoclonus into a rhythmic one; in figure 4, II, 
the sporadic myoclonus of II a turns after 4 min into a rhythmic, rapid and high-amplitude myoclonus (fig. 4, II b). After 13 min the same case presents a rhythmic ocular myoclonus, very brief and of low amplitude (fig. 4, II c). Figure 4, III, shows another rhythmic ocular myoclonus: there exists a very rapid alternation between myocloniae with frequencies of 4 and $10 \mathrm{cps}$, the whole episode occurring during $25 \mathrm{sec}$. One can observe the important EEG concomitant changes.

5. Eye movements similar to those observed in paradoxical sleep can be seen in figure 5 a where the EEG has diminished amplitude. Triangularshaped waves (' saw-tooth ' form) exist. But these episodes are too short $(20 \mathrm{sec}$ ) to be rapid eye movement (REM) sleep and their existence appeared to be conditioned by the phases of Cheyne-Stokes breathing. Thus, in figure $5 \mathrm{~b}$ one can see such an episode only during the apnea phase of Cheyne-Stokes breathing. There is no relation between coma and the different stages of sleep [1, 4] but the described episodes are, from the polygraphic point of view, similar to REM stages. We think that during the apnea phase of Cheyne-Stokes breathing the increasing hypoxia causes increasing excitability of still active areas of the patient's brain in coma states. These formations are in the ponto-bulbar region which also contains the inferior part of the reticular formation including the locus coeruleus.

Free Communications: I. Clinical Investigations 604

Fig. 3. a A short episode (1-2 min) of active ocular myoclonus, $15 \mathrm{~h} 26 \mathrm{~min}$ before clinical death, $b$ An epidode of 18 min of active ocular myocloniae; in the 5 sections the amplitude of the myocloniae becomes greater and greater.

Fig. 4. I: sporadic and slow ocular movements without relation to breathing. II: $\mathrm{a}=$ sporadic but rapid and ample ocular movements, $\mathrm{b}=$ after 4 min the sporadic myoclonus turns into a rhythmic one. $\mathrm{c}=$ after $13 \mathrm{~min}$ from the beginning a rhythmic myoclonus. III: a rhythmic, alternant, ocular myoclonus with important concomitant EEG changes, especially on the parietal-temporal lines (RT-RP, LT-LP) (polyspikes and polyspike wave complexes of high amplitude).

Ajgian Investigations of Coma and Clinical Death 605

Fig. 5. a REM sleep aspect of EEG lines and ocular movements. Cheyne-Stokes. b An episode similar to REM, only in the apnea phase of Cheyne-Stokes.

Fig. 6. a Three minutes after clinical death. No cardiac activity; considerable EEG activity, b Same case after 16 min: greater amplitude and frequency of potentials, c Coma state with left hemiplegia. Isoelectric right lines (22 min after clinical death), $d$ The same patient, 37 min after clinical death. 
In this situation, the variability of the functional state of the locus coeruleus determines the appearance of characteristic ' saw-tooth ' graphoelements on the EEG but it could not excite the visuocalcarine, geniculate, oculomotor and limbic structures with which it achieves in normal state the electro-clinical complex of the REM stage. When the patient passes from the apnea phase to breathing the excitability of locus coeruleus changes and the EEG aspect of ' REM ' disappears.

The 5 categories of ocular movements in cerebral-vascular coma constitute the expression of the ponto-bulbar reticular hyperexcitability which is transmitted to the different structures of importance in conjugate ocular movements. The excitation of one or of the other of these oculomotor

\section{Free Communications: I. Clinical Investigations 606}

structures determines which type of movement, i.e. the oscillating movements, active ocular myoclonus, sporadic and rhythmic ocular myoclonus or the eye movements similar to those observed in the paradoxical sleep, is preponderant.

Concerning activity of the brain after clinical death we must point out: (1) that cessation of cardio-respiratory activity does not occur simultaneously with cessation of the electric activity of the brain. Therefore, from the polygraphic point of view, clinical death and the electric death of the brain does not occur at the same time. We have often noticed EEG activity after the definitive cessation of cardio-respiratory activity and in some cases the graphoelements showed an increase of amplitude during the minutes following the clinical death (fig. $6 \mathrm{a}-\mathrm{b}$ ), and (2) this electric activity is not equal on all the EEG lines; it is flatter and slower on the lines of the damaged hemisphere and disappears from this area earlier than on the derivations of the intact hemisphere (fig. $6 \mathrm{c}-\mathrm{d}$ ). That means that the death of the brain does not occur at the same time in all encephalic structures and we can say that the electric death of the brain occurs first in the hemisphere with a hemorrhagic or ischemic accident.

\section{References}

1 Asgian, B.; Sipos, C. i Popoviciu, L.: Dinamica modificarilor poligrafice !n comele vasculare cerebrale, pina la moartea clinica. A XH-a sesiune EEG, EMG \$i neurofiziologie clinica (in press).

2 Lance, J. W. and Adams, R. D.: The syndrome of intention or action myoclonus as a sequel to hypoxic encephalopathy. Brain 86 (I): 111-136 (1963).

3 Popoviciu, L.; Asgian, B.; Corfariu, O.; Gaspar, St.; Pascu, I. i Kikely, P.: 
Corelafii clinice electropoligrafice de somn $\$$ i electromiografice in unele sindroame mioclonice. Rev. med. Tirgu-Mure? 16: 3-4, 264-268 (1970); translation in Electroenceph. clin. Neurophysiol. 31: 521 (1971).

4 Popoviciu, L.; Pascu, I.; Lazar, L.; Sipos, C. et Moldoveanu, M.: Recherches polygraphiques sur les relations du sommeil et les troubles chroniques de la conscience. Arch. Un. med., Balkan. 9: 5-6, 603-606 (1971).

Author's address: Dr. B. Asgian, Neurological Clinic, G. Marinescu St., 38, TtrguMures (Roumania) 